\title{
Influence of Milling Process Parameters on Machined Surface Quality of Carbon Fibre Reinforced Polymer (CFRP) Composites Using Taguchi Analysis and Grey Relational Analysis
}

\author{
I.S.N.V.R. Prasanth ${ }^{1}$, S. Nikitha ${ }^{1}$, R. Pulsingh ${ }^{1}$, M. Sampath ${ }^{1}$, Shaik Bazee ${ }^{1}$, \\ Chandra Mouli Badiganti ${ }^{2 *}$
}

${ }^{1}$ Department of Mechanical Engineering, Guru Nanak Institute of Technology, Hyderabad, INDIA
${ }^{2}$ Department of Mechanical Engineering, RISE Krishna Sai Prakasam Group of Institutions, Ongole, INDIA

DOI: https://doi.org/10.30880/ijie.2021.13.06.007

Received 12 May 2020; Accepted 26 April 2021; Available online 31 August 2021

\begin{abstract}
The article presents the milled surface quality of Uni-Directional Carbon Fibre Reinforced Polymer (UDCFRP) composites from Taguchi's and grey relational analysis. The novelty is demonstrating the possibility of detecting the surface defects in polymer composites during milling using SEM analysis. The material used for this study is UD-CFRP composite laminates and made by hand-layup process. All the milling operations were carried out using a solid tungsten carbide end milling tool and experiments conducted on CNC milling machine. Taguchi L9, 3-level orthogonal array was considered for experimentation. Analysis of Variance (ANOVA) was conducted to explore the significance of each individual input process parameters on multiple performance characteristics. Optimal process parameters are thoroughly validated by grey relational grade achieved by the grey relational analysis for multi performance characteristics. Finally, experimental results were correlated and analyzed with scanning electron micrographs using Scanning Electron Microscope (SEM).
\end{abstract}

Keywords: UD-CFRP composites, Machined surface quality, Machining damage, SEM, Surface integrity.

\section{Introduction}

Carbon Fibre Reinforced Polymer (CFRP's) can be costly to produce but are widely used where a greater degree of strength and durability is needed, such as aerospace, good shipbuilding, automotive, civil engineering, sports equipment, and a growing number of consumers and technological applications. Machining of composite materials is a moderately complex mission owing to its heterogeneity and the number of problems elevated such as surface failures, and inters laminar defects. Due to material characteristics and based on selection of process parameters, these damages might be caused. The processing operations in the manufacturing sector have mainly been used in fibre-strengthened plastics, since components made of composite materials are frequently made by net form, which often requires the removal of excess material to control tolerances. Milling is a suitable process to produce high-quality surface areas well defined in secondary manufacturing products with a closed tolerance [1]. The machinability of fibre-reinforced polymers (FRPs) depends heavily on the type of fibre integrated into a composite. Mechanical and thermal characteristics are extremely important for machining FRPs. Mechanics of cutting composites have a greater effect on the choice of cutting tools, machining parameters and other machinable conditions (cutting material and geometry).

Knowing that the right resources are gathered with the right material is important. The knowledge of cutting processes is important in the context of cutting mechanics and the machinability assessment in milling [1,2]. Composites such as Carbon Fibre Polymers (CFP), made from carbon fibres to strengthen plastic resin patterns such as epoxy resin, 
have excellent properties such as light weight, high resistance, and high stiffness. Such properties make the applications in aerospace particularly desirable [2]. On the other hand, carbon fibres withstand temperatures up to $3000^{\circ} \mathrm{C}$ until degradation of the structure is initiated. Surface roughness (SR) is a measure of quality that increases dimensional accuracy, volume of production and costs of production. In order to achieve a certain surface consistency, research work has been carried out over decades [3,4]. Sreejith et al. [5] conducted experimental studies on face turning of ablative carbon / phenol composites. This research has to do with knowing the thermal characteristics in machining phase [5]. Everstine and Rogers [6] have presented theoretical analysis that would help to solve problems in deformation and chip formation mechanisms during the machining of FRPs in 1971, later on lot of research work has been made. Koplev et al. [7], Kaneeda [8] and Puw and Hocheng [9] concluded that the main cutting mechanisms are strongly associated with fibre geometry. Santhana krishnan et al. [10] conducted experiments with K-10 carbide tools in front of GFRP, CFRP and Kevlar fiber composite laminates. The experimental results compared and evaluated with machined morphology of the surface. Also to illustrate the tool wear and material removal mechanisms, Ramulu et al. [11] carried out a study on polymer composites machining to achieve better surface finishing, which found better results at higher cutting speeds. Hocheng et al. [12] examined the effect on machining efficiency, cutting forces, and tool wear by fiber orientation. He concluded that due to their fragility, fibre factures exist. It must be cut parallel to the path of the fibres for unidirectional fiber-reinforced composites. The experiments with Taguchi and the multi-target optimization criterion were conducted by Enemuoh et al. [13]. The parameters of cutting that do not damage fiber enhanced plastics and these can be optimized with low feed and high speed. Paulo Davim et al.[14] investigated the effect and optimization of cutting parameters (speed and feed rate) in order to obtain the desired precise cut strength, thrust power, delamination factor (DLF) and SR for GFRP's. The manufactured technique was used to develop a series of experiments based on Taguchi technique. The effect and final surface quality analysis of GFRP composite laminates was explained by I.S.N.V.R. Prasanth et al., they have used modeled carbide end milling tools [15]. Sheik Ahmad et al. [16] has studied the comprehensive model for orthogonal milling of unidirectional composites with different fibre orientations. Devi Kalla [17] examined the techniques of mechanistic modeling of CFRP cutting simulations with a helical milling. By converting unique cutting energy from orthogonal cutting to obliquity cutting, a technique has been developed to estimate cutting forces. I.S.N.V.R. Prasanth et al. [18] investigated the effect of the process parameters on performance characteristics on unidirectional GFRP composites by Taguchi's technique. Moreover, SEM analysis on machined surface morphology has also validated with the test results [18]. Deng et al. proposed an analysis of Gray-relationship to solve the complicated performance problems in order that incomplete and uninformative models can achieve better results [19].

Palani kumar et al. utilized Taguchi - Grey relational analysis (GRA) to make simpler to predict the effect of combined input process parameters to optimize the multi performance characteristics. All the experiments were performed on GFRP composites with carbide K-10 tool [20]. Gupta and Kumar et al. optimized process input parameters with multi-response characteristics including SR and material extraction velocity with GRA on GFRP composites with the polycrystalline diamond tool [21]. Rao et al. used Taguchi L9 with GRA to minimize cutting force, SR, and maximize tool life in order to optimize the input factor such as cutting speed, feed, cutting depth and approach angles of the Inconel 718 material in face milling process [22].

Arun et al. have conducted composite turning experiments with cemented carbide to optimize the spindle speed, feed and depth of the cut. With GRA several performance properties, such as SR and material removal levels, are effectively analyzed and simplified [23]. Jenarthanan et al. conducted the desirability functional analysis (DFA) and Grey Relational Analysis (GRA) on performance response factors such as delamination factor (DLF), SR and machining force to optimize mechanizing parameters (spindle speed, fibre orientation angles, helix angle and feed speed). GFRP composite framing experiments with various helix angles were conducted using solid carbide cutters [24]. On the other hand, Naresh et al. attempt to optimize CNC system parameters. The experiments have been developed and conducted using the L27 orthogonal array of Taguchi on GFRP composites [25].

Selvam et al. carried out all experiments on CNC milling machine. In order to optimize machine process parameters i.e., cutting speed and feed speed to reduce machine forces, SR, torque cutting and delamination of GFRP laminates [26]. Rajguru et al. highlighted the perforation of GFRP's composite material to minimize SR and thrust resistance. In this respect, Grey's theory of relationships is linked to Taguchi's approach for solving the multi-objective optimization problem [27]. Vinod kumar et al. [28] investigated the influence of fibre orientation on surface integrity of GFRP composites with various rake angled end milling tools. Machined surface quality also evaluated with SEM graphs. He concluded that better results were obtained at lower machining forces; lower rake angle of the tool particularly for milling of fibre orientation angle is less than $90^{\circ}$.

However, the previous reports did not find Grey- Taguchi method to optimize the multi performance characteristics in milling of uni-directional CFRP composite laminates. To fulfill this research gap, further investigations have been performed. The aim of this study is the analysis and assessment of the effects of the input process parameters such as spindle speed, feed rate, and depth of cut on SR and DLF with a CNC carbide-end milling tool. With Gray relationship analysis, the Taguchi L9 orthogonal array is effective in optimizing process parameters for the resolution of multiple response problems. ANOVA is also conducted to know the importance and contribution of each input factor to its different performance characteristics. Consequently, confirmation tests attempted to validate the test results. Finally, morphology of milled surface quality was illustrated with SEM graphs. 


\section{Experimental Procedure}

The $5 \mathrm{~mm}$ thick composite laminate was produced in the manual laying process. During the manufacture of composite laminates, the flat $5 \mathrm{~mm}$ thick mold panel is fitted with eight layers of a one-way material of fibre $300 \mathrm{~mm}$ long/300 mm wide. In this manufacturing process L-12 epoxy resin and K-6 hardener are used. A blend of 10:1 epoxy resin and hardener has been mixed in a glass cup to be mixed fully. The ready mix was then poured into and compressed into preformed carbon. After 5 hours the resin has been cured at room temperature and ready laminates were cut into 5 $\mathrm{mm}$ thickness to length of $100 \mathrm{~mm}$ x breadth of $100 \mathrm{~mm}$ for experimentation. In accordance with ASTM D2548-68, the average fibre volume 'Vf,' strengthened by $45 \%$ carbon fibre, was found to be approximately 0.45 . The physical and mechanical characteristics of a $5 \mathrm{~mm}$ thick UD-CFRP composite laminate have been tested in accordance with ASTM D792 and ASTM D2548-68 requirements. The values of the measured sample were 1.76g /cc, 3.75Gpa or $231 \mathrm{GPa}$, for its density, tensile strength and tensile modulus.

Table1 - Assignment of the levels to the factors

\begin{tabular}{clccccc}
\hline \multirow{2}{*}{ Factors } & \multirow{2}{*}{ Process Parameters } & \multirow{2}{*}{ Units } & \multirow{2}{*}{ Notation } & \multicolumn{4}{c}{ Levels } \\
\cline { 5 - 7 } & & & & $\mathbf{1}$ & $\mathbf{2}$ & $\mathbf{3}$ \\
\hline A & Spindle speed & $\mathrm{rpm}$ & $\mathrm{N}$ & 1000 & 2500 & 4000 \\
B & Feed Rate & $\mathrm{mm} / \mathrm{min}$ & $\mathrm{f}$ & 100 & 200 & 300 \\
C & Depth of cut & $\mathrm{mm}$ & $\mathrm{t}$ & 0.5 & 1.5 & 2.5 \\
\hline
\end{tabular}

A total of nine experiments were planned according to Taguchi's L9 orthogonal array. Three major regulated parameters (spindle speed, feed rate, cutting depth) designed the experiment; each parameter had 3 levels and is shown in Table 1. In order to examine the effects of different machining process parameters, the Taguchi analysis considered the average value of the experimental response and the corresponding signal- to-ratio of noise $(\mathrm{S} / \mathrm{N})$. The $\mathrm{S} / \mathrm{N}$ ratio for Taguchi analysis is defined as the average (mean) and variables (standard deviation). With optimized variable input process parameters it was possible to obtain the lowest SR and DLF possible. Thus, the S / N ratio will be the "lower the better" category. Experiments have been made with a spindle power of $7.45 \mathrm{~kW}$ and maximum speed of $5000 \mathrm{rpm}$ CNC machine. Milling operations were performed under dry conditions to provide a diameter of $10 \mathrm{~mm}$ slots, using $10 \mathrm{~mm}$ diameter of solid carbide end milling tool. The experimental set-up is presented in Fig.1.

In addition, $S R\left(R_{a}\right)$ was considered a measure of surface quality and the three separate indicators at start, middle, and end points along the path of the instrument's feed on the vertical wall of milled slot were measured by means of the Mitutoyo SR tester. Table 2 indicates the cut off Center Line Average Method (CLA), and the transference duration is set to $0.5 \mathrm{~mm}$ and $5 \mathrm{~mm}$ in accordance with ISO 4287/1 with an average minimum number of 0.01 microns. The damage was determined with a $10 \mu \mathrm{m}$ precision travel microscope (ModelRVM-201) in the perpendicular direction of the specimen. Factors for delamination $\left(\mathrm{F}_{\mathrm{D}}\right)$ were derived by taking the average value as per Devim et al. [29].

$\operatorname{DLF}\left(\mathrm{F}_{\mathrm{D}}\right)$ was calculated using formulae, $\mathrm{F}_{\mathrm{D}}=\mathrm{W}_{\mathrm{Max}} / \mathrm{W}$---------- 1.

Where $\mathrm{W}_{\text {Max }}=$ Width of a slot after machining, and $\mathrm{W}=$ Actual width of a cut.

Finally, SEM was used to examine the surface morphology of machined UD-CFRP composite laminates.

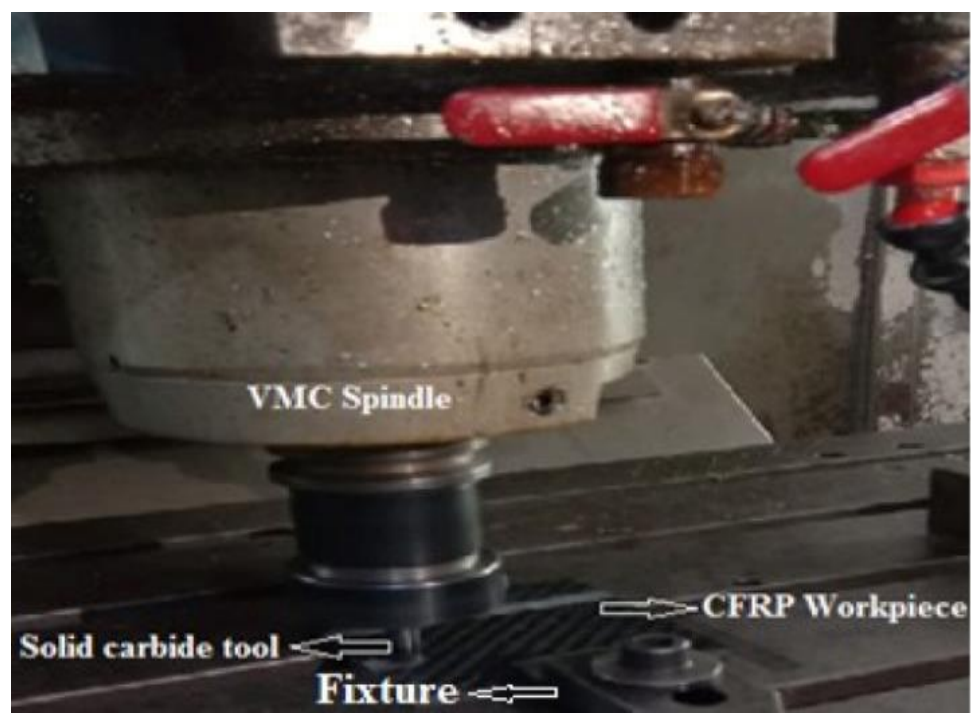

Fig.1 - CFRP composite laminate fixed in the CNC Milling machine 
Table 2 - Milling parameters with their levels

\begin{tabular}{cccccc}
\hline Exp No & A & B & C & $\begin{array}{c}\text { Surface roughness } \\
\text { (SR) }\end{array}$ & Delamination factor (DLF) \\
\hline 1 & 1000 & 100 & 0.5 & 1.41 & 1.05 \\
2 & 1000 & 200 & 1.5 & 1.81 & 1.08 \\
3 & 1000 & 300 & 2.5 & 2.36 & 1.12 \\
4 & 2500 & 100 & 1.5 & 1.94 & 1.09 \\
5 & 2500 & 200 & 2.5 & 2.15 & 1.10 \\
6 & 2500 & 300 & 0.5 & 1.60 & 1.07 \\
7 & 4000 & 100 & 2.5 & 2.41 & 1.15 \\
8 & 4000 & 200 & 0.5 & 1.26 & 1.08 \\
9 & 4000 & 300 & 1.5 & 1.61 & \\
\hline
\end{tabular}

\section{Optimizing Individual Performance Characteristics}

\subsection{Determination of Optimum Process Parameters for Surface Roughness (SR)}

The orthogonal array of Taguchi L9 is used to set optimal process parameters. Experiment results have been demonstrated by $\mathrm{S} / \mathrm{N}$ ratio and ANOVA analysis. The lower-the- better Taguchi is to know the optimum process parameter for SR. Table 3 shows the SR and the S / N ratio.

Table 3 - Results of the experiments for $\mathrm{SR}$ and $\mathrm{S} / \mathrm{N}$ ratio

\begin{tabular}{cccccc}
\hline Exp No & A & B & C & $\begin{array}{c}\text { Surface roughness } \\
(\mathbf{S R})\end{array}$ & S/N ratio \\
\hline 1 & 1000 & 100 & 0.5 & 1.41 & 5.214 \\
2 & 1000 & 200 & 1.5 & 1.81 & 5.325 \\
3 & 1000 & 300 & 2.5 & 2.36 & 4.985 \\
4 & 2500 & 100 & 1.5 & 1.94 & 5.415 \\
5 & 2500 & 200 & 2.5 & 2.15 & 5.628 \\
6 & 2500 & 300 & 0.5 & 1.6 & 5.214 \\
7 & 4000 & 100 & 2.5 & 2.41 & 3.275 \\
8 & 4000 & 200 & 0.5 & 1.26 & 7.124 \\
9 & 4000 & 300 & 1.5 & 1.61 & 6.278 \\
\hline
\end{tabular}

Table 4 - Response table for mean $\mathrm{S} / \mathrm{N}$ ratio $\mathrm{SR}$

\begin{tabular}{|c|c|c|c|c|c|c|}
\hline \multirow{2}{*}{ Factors } & \multirow{2}{*}{ Process Parameters } & \multicolumn{4}{|c|}{ Mean S/N ratio } & \multirow{2}{*}{ Rank } \\
\hline & & Level 1 & Level 2 & Level 3 & Max-Min & \\
\hline $\mathrm{A}$ & Spindle speed & -5.199 & -5.496 & -4.595 & 0.901 & 2 \\
\hline B & Feed rate & -5.46 & -4.603 & -5.226 & 0.857 & 3 \\
\hline $\mathrm{C}$ & Depth of cut & -3.025 & -5.015 & -7.249 & 4.224 & 1 \\
\hline
\end{tabular}

Total mean $\mathrm{S} / \mathrm{N}$ ratio -5.096

\subsection{S/N Ratio Analysis for Surface Roughness}

The experimental design is described as an orthogonal array, thus separating the influence of individual process parameters at various levels. The research aims to minimize SR and therefore to know the optimal combined process parameter for SR with the lower-the-better characteristic is applied. From Table 4 of the response, the mean $\mathrm{S} / \mathrm{N}$ ratio for SR preferred optimum process parameters such as spindle speed at level-2, feed rate at level-1 and cut depth at level3 i.e., A2B1C3. The primary S/N effect plot for SR is detailed in Fig.2. 


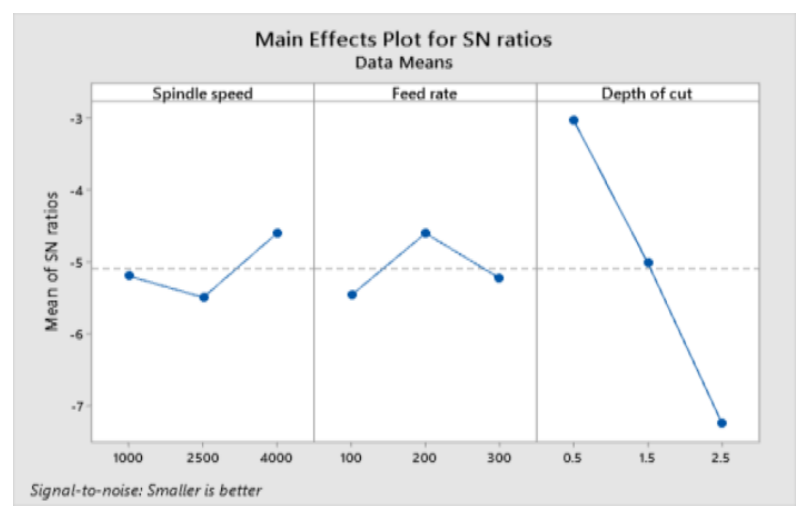

Fig.2 - Mean S/N graph for surface roughness

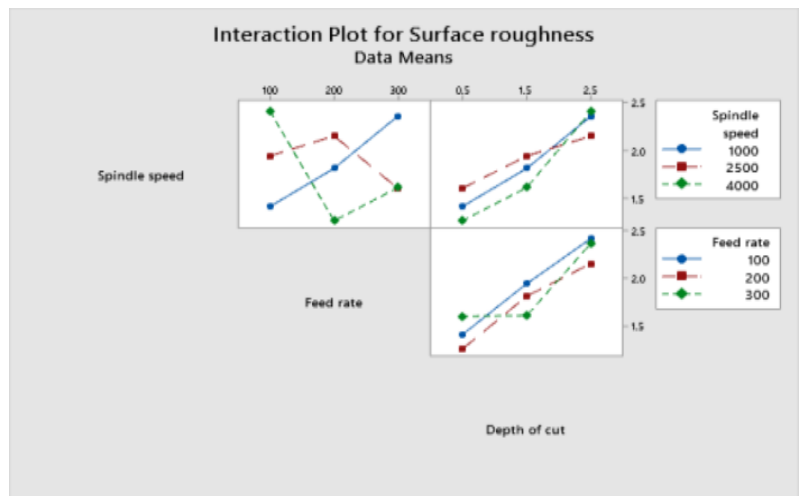

Fig.3 - Interaction plot for surface roughness

The relationship between the process parameters and SR is shown in the figure 3 . The spindle speed was approximately linear with no feed rate interaction. Yet cutting depth is an important parameter that has a heavy spindle speed interaction. Similar interaction effect for feed rate and cutting depth is observed. And SR is observed to decrease significantly from 2500rpm to 4000rpm. Desirable SR below $1.25 \mu \mathrm{m}$ is reached at a high spindle speed of 4000rpm, $200 \mathrm{~mm} / \mathrm{min}$ feed rate and a low cutting depth of $0.5 \mathrm{~mm}$.

\subsection{ANOVA for Surface Roughness}

ANOVA is used to evaluate the significance of each process parameter on the response. The ANOVA results are presented in Table 5. It shows that the depth of cut with a value of $\mathrm{P}$ is less than 0.05 and the result is $95 \%$ confidence. Since the cutting depth is highly influenced parameter and followed by the feed rate and spindle speed for SR.

Table 5 - ANOVA table for SR.

\begin{tabular}{lccccc}
\hline \multicolumn{1}{c}{ Source } & DF & SS & MS & F & P \\
\hline Spindle speed & 2 & 0.03 & 0.015 & 0.069 & 0.934 \\
Feed rate & 2 & 0.05 & 0.025 & 0.117 & 0.892 \\
Depth of cut & 2 & 1.1827 & 0.5913 & 23.435 & 0.001 \\
Error & 2 & 0.1514 & 0.0252 & & \\
Total & 8 & 1.4141 & & & \\
\hline
\end{tabular}

$\mathrm{S}=0.188886 \quad \mathrm{R}-\mathrm{sq}=94.65 \% \quad \mathrm{R}-\mathrm{sq}(\operatorname{adj})=78.61 \%$

\subsection{Validation Test for SR}

Table 6 shows optimal combined process parameters for the confirmatory test results. The machined workpiece SR is reduced from $1.41 \mu \mathrm{m}$ to $1.24 \mu \mathrm{m}$. The increase in the $\mathrm{S} / \mathrm{N}$ ratio from initial combined process parameters to optimal combined process parameter here is $1.906 \mathrm{~dB}$ and the reduction of SR is $12 \%$. 
Table 6 - Conformation results for SR

\begin{tabular}{|c|c|c|c|}
\hline \multicolumn{2}{|c|}{ Initial process parameter } & \multicolumn{2}{|c|}{$\begin{array}{c}\text { Optimal process } \\
\text { parameters }\end{array}$} \\
\hline & & Prediction & Experiment \\
\hline Level & $\mathrm{A} 1 \mathrm{~B} 1 \mathrm{C} 1$ & & $\mathrm{~A} 2 \mathrm{~B} 1 \mathrm{C} 3$ \\
\hline $\mathrm{Ra}$ & 1.41 & & 1.24 \\
\hline $\mathrm{S} / \mathrm{N}$ ratio $(\mathrm{dB})$ & 5.214 & 7.32 & 7.12 \\
\hline
\end{tabular}

Improvement of $\mathrm{S} / \mathrm{N}$ ratio $=1.906 \mathrm{~dB}$

\subsection{Optimum Process Parameters for Delamination Factor (DLF)}

Similarly, experimental design is defined as an orthogonal array for DLF thus separating the importance of different process parameters at different levels. The aim of the research is to reduce the DLF to a minimum and therefore, to know the optimum combined process parameter for DLF is the less is lower-the-better performance characteristic. Table 7 shows the S/N ratio for DLF response. The mean S/N ratio for DLF is indicated in Table 8, and optimized combined process parameters like spindle speed at level 3, feed rates at level 2 and cut depth at level 1 i.e. A3B2C1 were arrived.

Table7 - Results of the experiments for DLF and S/N ratio

\begin{tabular}{|c|c|c|c|c|c|}
\hline Exp.No. & $\mathbf{A}$ & B & $\mathbf{C}$ & Delamination factor (DLF) & $\mathrm{S} / \mathrm{N}$ ratio \\
\hline 1 & 1000 & 100 & 0.5 & 1.05 & 0.625 \\
\hline 2 & 1000 & 200 & 1.5 & 1.08 & 0.724 \\
\hline 3 & 1000 & 300 & 2.5 & 1.12 & 0.651 \\
\hline 4 & 2500 & 100 & 1.5 & 1.09 & 0.758 \\
\hline 5 & 2500 & 200 & 2.5 & 1.1 & 0.562 \\
\hline 6 & 2500 & 300 & 0.5 & 1.07 & 0.468 \\
\hline 7 & 4000 & 100 & 2.5 & 1.15 & 0.358 \\
\hline 8 & 4000 & 200 & 0.5 & 1.01 & 1.056 \\
\hline 9 & 4000 & 300 & 1.5 & 1.08 & 0.698 \\
\hline
\end{tabular}

Table 8 - Response table for mean $\mathrm{S} / \mathrm{N}$ ratio $\mathrm{DLF}$

\begin{tabular}{cllllll}
\hline \multirow{2}{*}{ Factors } & \multirow{2}{*}{ Process parameters } & \multicolumn{4}{c}{ Mean S/N ratio } & \multirow{2}{*}{ Rank } \\
\cline { 3 - 6 } & & Level 1 & Level 2 & Level 3 & Max-Min \\
\hline A & Spindle speed & -0.69 & -0.72 & -0.65 & 0.065 & 3 \\
B & Feed rate & -0.79 & -0.52 & -0.74 & 0.267 & 2 \\
C & Depth of cut & -0.36 & -0.69 & -1 & 0.642 & 1 \\
\hline
\end{tabular}

\subsection{Analysis of S/N Ratio for DLF}

The main effect plot for the $\mathrm{S} / \mathrm{N}$ ratio is shown in Fig.4. Figure shows the interaction of the process parameters on the DLF. There was an approximate linear curve with no interference with the feed rate of the spindle speed. But cut depth is an important parameter with strong spindle speed interaction. Similar interaction plot for feed rate and cut depth is observed. The spindle speed is least interaction with feed. The DLF is less than 1.05 and reaches at a high spindle rate of 4,000rpm, a moderate feeding rate of $200 \mathrm{~mm} / \mathrm{min}$ and a low cutting depth of $0.5 \mathrm{~mm}$. 


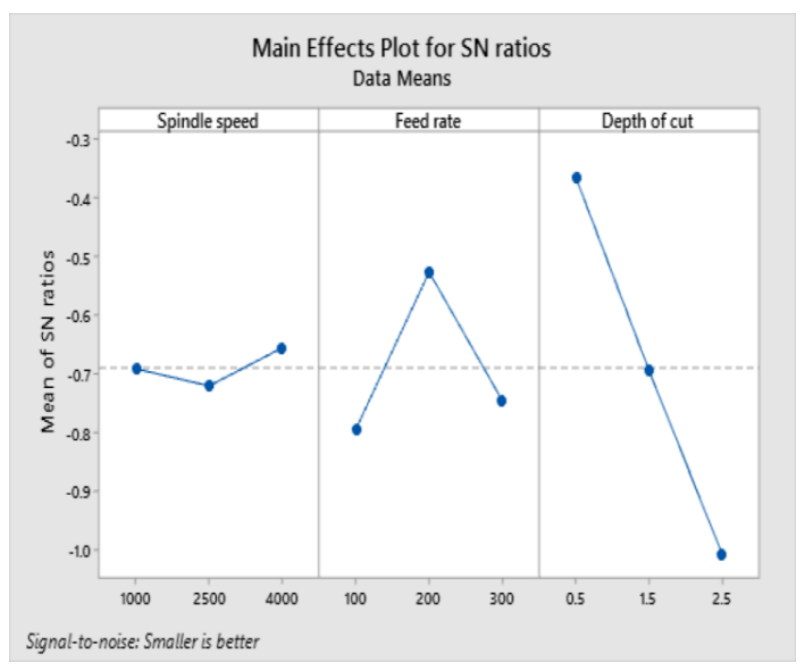

Fig. 4 - Mean S/N graph for delamination factor

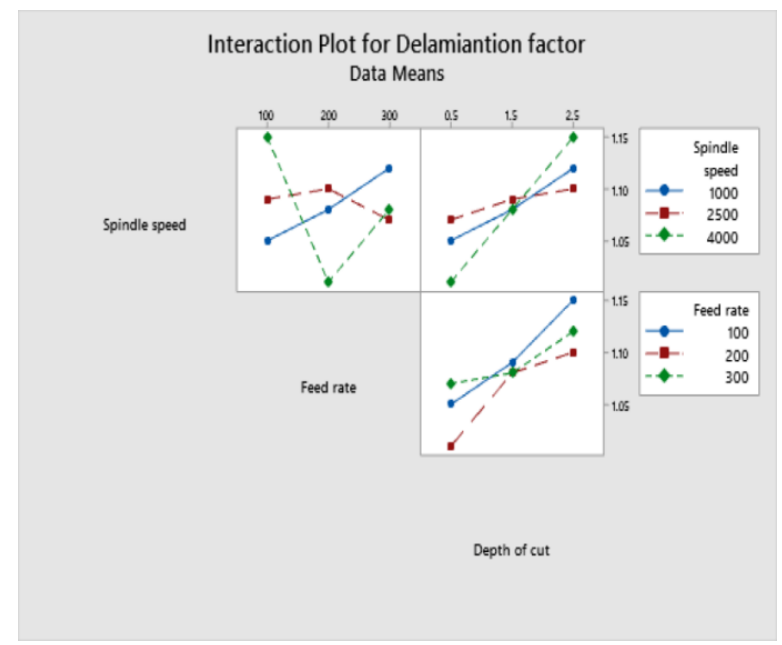

Fig. 5 - Interaction plot for delamination factor

\subsection{ANOVA for Delamination Factor}

Table 9 shows ANOVA results for DLF. It is obvious that the depth of cut with a $\mathrm{P}$ value of less than 0.05 is significant at a confidence level of 95 percent. Since the cutting depth is highly influenced and followed by the feed rate and spindle rate on DLF.

Table 9 - ANOVA table for DLF

\begin{tabular}{lccccc}
\hline \multicolumn{1}{c}{ Source } & DF & SS & MS & F & P \\
\hline Spindle speed & 2 & 0.0001 & 0 & 0.016 & 0.984 \\
Feed rate & 2 & 0.0019 & 0.0009 & 0.512 & 0.623 \\
Depth of cut & 2 & 0.0096 & 0.0048 & 9 & 0.016 \\
Error & 2 & 0.0032 & 0.0005 & & \\
Total & 8 & 0.0148 & & & \\
\hline $\mathrm{S}=0.0251661$ & R-sq=90.10\% & R-sq(adj) $=60.42 \%$
\end{tabular}

\subsection{Validation Test for DLF}

Table 10 shows the test results from optimal combined process parameters. The machined workpiece DLF is reduced from 1.05 to 1.01. Increasing the $\mathrm{S} / \mathrm{N}$ ratio from initial combined process parameters to the optimum combined process parameter is $0.375 \mathrm{~dB}$ and reducing the DLF by $1.5 \%$ from confirmation tests. 
Table 10 - Conformation results for DLF

\begin{tabular}{lccc}
\hline \multirow{2}{*}{ Initial process parameter } & \multicolumn{2}{c}{ Optimal process parameters } \\
\cline { 3 - 4 } & & Prediction & Experiment \\
\hline Level & $\mathrm{A} 1 \mathrm{~B} 1 \mathrm{C} 1$ & & $\mathrm{~A} 3 \mathrm{~B} 2 \mathrm{C} 1$ \\
$\mathrm{FD}$ & 1.05 & & 1.01 \\
$\mathrm{~S} / \mathrm{N}$ ratio $(\mathrm{dB})$ & 0.625 & 1.14 & 1 \\
\hline
\end{tabular}

Advancement of $\mathrm{S} / \mathrm{N}$ ratio $=0.375 \mathrm{~dB}$

\section{Grey relational analysis}

Complication in multiple performance characteristics i.e., SR and DLF can be easily converted into single performance characteristic and improved with grey relational grade. Systematic approach to optimize the design of experiments Taguchi with GRA has been performed in this study [23].

Table 11 - Grey relational grade (GRG) table

\begin{tabular}{|c|c|c|c|c|c|c|c|c|c|}
\hline \multirow{2}{*}{ Exp.No } & \multicolumn{2}{|c|}{ Responses } & \multicolumn{2}{|c|}{$\begin{array}{l}\text { Grey Relational } \\
\text { generation }\end{array}$} & \multicolumn{2}{|c|}{ Evaluation of $\Delta o i$} & \multicolumn{2}{|c|}{$\begin{array}{c}\text { Grey Relational } \\
\text { coefficient }(\psi)\end{array}$} & \multirow[t]{2}{*}{$\begin{array}{c}\text { Grey } \\
\text { relational } \\
\text { grade }\end{array}$} \\
\hline & SR & DLF & SR & DLF & SR & DLF & SR & DLF & \\
\hline 1 & 1.41 & 1.05 & 0.124512 & 0.085456 & 0.15642 & 0.65422 & 0.254562 & 0.36251 & 0.308537 \\
\hline 2 & 1.81 & 1.08 & 0.232543 & 0.235874 & 0.83256 & 0.95321 & 0.356831 & 0.31429 & 0.335559 \\
\hline 3 & 2.36 & 1.12 & 0.623176 & 0.854632 & 0.20387 & 0.89568 & 0.858686 & 0.24599 & 0.552338 \\
\hline 4 & 1.94 & 1.09 & 0.541268 & 0.745681 & 0.80324 & 0.52655 & 0.741584 & 0.32581 & 0.533699 \\
\hline 5 & 2.15 & 1.1 & 0.785612 & 0.235698 & 0.63028 & 0.68935 & 0.328964 & 0.45206 & 0.390513 \\
\hline 6 & 1.6 & 1.07 & 0.095243 & 0.415231 & 0.96321 & 0.65897 & 0.254168 & 0.53692 & 0.395543 \\
\hline 7 & 2.41 & 1.15 & 0.189455 & 0.145126 & 0.45231 & & 0.865402 & 0.32056 & 0.592982 \\
\hline 8 & 1.26 & 1.01 & 1 & 1 & 0 & 0 & 1 & 1 & 1 \\
\hline 9 & 1.61 & 1.08 & 0.362541 & 0.745685 & 0.53219 & 0.9832 & 0.252524 & 0.35248 & 0.302503 \\
\hline
\end{tabular}

In GRA, the normalized data processing for SR and DLF corresponding to lower-the-better criterion is determined as

$$
x i(k)=\frac{\operatorname{maxy} i(k)-y i(k)}{\operatorname{maxyi}(k)-\operatorname{miny} i(k)}
$$

Eq. (1) is used for the "lower-the-better" response, where $\mathrm{xi}(\mathrm{k})$ is the value after grey relational generation, min yi $(\mathrm{k})$ is the smallest value of yi(k) for the kth response, and the max yi(k) is the largest value of yi(k) for the kth response. An ideal sequence is $x o(k)$ where $(k=2$ for SR and DLF). The definition of grey relational grade in the course of GRA is to reveal the relational degree between the nine sequences $[x o(k)$ and $x i(k), i=1,2,3 \ldots . .9$ ]. The grey relational coefficient $\xi \mathrm{i}(\mathrm{k}) \mathrm{can}$ be expressed as

$$
\xi i(k)=\frac{\Delta \min +\psi \Delta \max }{\Delta o i(k)+\psi \Delta \max }
$$

Where $\Delta \mathrm{oi}=$ xo $(\mathrm{k})$-xi $(\mathrm{k})$ difference of the absolute value between xo $(\mathrm{k})$ and $\mathrm{xi}(\mathrm{k})$;

$\Psi=$ distinguishing coefficient between zero and one, the purpose of which is to weaken the effect of $\Delta$ max when it gets too big, and thus enlarges the difference significance of the relational coefficient. In the present case, $\psi=0.5$ is used.

After averaging the grey relational coefficients, the grey relational grade $\gamma \mathrm{i}$ can be calculated as follows:

$$
\gamma i=(1 / n) \sum_{k=1}^{n} \xi i(k)
$$


Where $n=$ number of responses to the process. The higher value is the strongest relation between the ideal sequence $\mathrm{x} 0(\mathrm{k})$ and the given sequence $\mathrm{xi}(\mathrm{k})$. The ideal sequence $\mathrm{x} 0(\mathrm{k})$ was already stated as the best process response in the experimental layout. The higher gray relation grade means that the respective combination of parameters is closer to the optimal. Table11 demonstrates the determination of the Grey relational grade.

\subsection{Optimum Process Parameters for the Gray Relational Grade}

Table12. S/N ratio and grey relational grade of performance characteristics

\begin{tabular}{clllcl}
\hline Exp. No. & A & B & C & Grey-relational grade & $\begin{array}{l}\text { S/N } \\
\text { ratio }\end{array}$ \\
\hline 1 & 1000 & 100 & 0.5 & 0.308537 & -2.126 \\
2 & 1000 & 200 & 1.5 & 0.3355585 & -2.014 \\
3 & 1000 & 300 & 2.5 & 0.5523375 & -1.775 \\
4 & 2500 & 100 & 1.5 & 0.533699 & -1.783 \\
5 & 2500 & 200 & 2.5 & 0.3905125 & -1.785 \\
6 & 2500 & 300 & 0.5 & 0.395543 & -1.798 \\
7 & 4000 & 100 & 2.5 & 0.5929815 & -1.654 \\
8 & 4000 & 200 & 0.5 & 1 & -0.856 \\
9 & 4000 & 300 & 1.5 & 0.302503 & -2.325 \\
\hline
\end{tabular}

\subsection{Analysis of S/N Ratio For Grey Relational Grade}

The S/N ratio performance characteristics of GRG are represented in Table12. The effect of process parameters on GRG of CFRP composite laminates were observed in response Table13. Minimized performance characteristics obtained at optimal combined process parameters a spindle speed at level-3, feed rate atlevel-2 and depth of cut at level-1 i.e. A3B2C1 as shown in Fig. 6.

Table 13 - Response table of mean $\mathrm{S} / \mathrm{N}$ ratio for Grey relational grade

\begin{tabular}{ccccccc}
\hline \multirow{2}{*}{ Factors } & \multirow{2}{*}{ Process parameters } & \multicolumn{4}{c}{ Mean S/N ratio } & \multirow{2}{*}{ Rank } \\
\cline { 3 - 6 } & & Level 1 & Level 2 & Level 3 & Max-Min & \\
\hline A & Spindle speed & -1.698 & -1.985 & -1.412 & 0.573 & 3 \\
B & Feed rate & -1.795 & -1.213 & -1.652 & 0.582 & 2 \\
C & Depth of cut & -2.354 & -1.785 & -1.456 & 1.141 & 1 \\
\hline
\end{tabular}

Total mean S/N Ratio $=-1.705 \mathrm{db}$

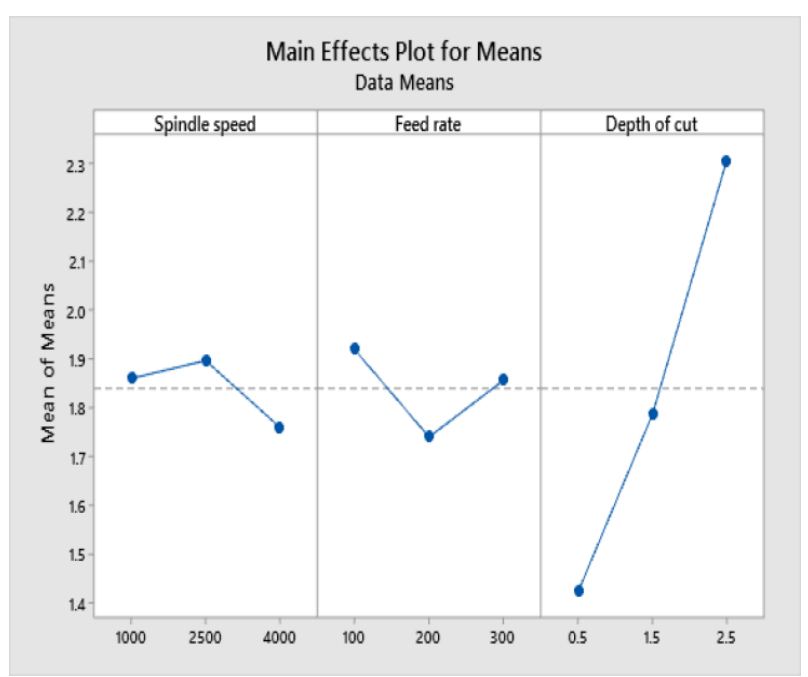

Fig. 6 - Effect of process parameters on Grey relational grade 


\subsection{ANOVA for Grey Relational Grade}

The optimal designed parameters effecting RA and DLF shall be known by ANOVA. Analysis was carried out for a meaning level of 5 percent. The $\mathrm{P}$ - value depth of the cut is below 0.05 , therefore significant at 95 percent confidence level and is shown in Table14. Therefore, we confirmed that cutting depth is the main parameter, followed by feed rate and spindle speed, which is reduced to RA and DLF.

Table14 - ANOVA for grey relational grade

\begin{tabular}{lccccc}
\hline \multicolumn{1}{c}{ Source } & DF & SS & MS & F & P \\
\hline Spindle speed & 2 & 0.0091 & 0.0045 & 0.94 & 0.513 \\
Feed rate & 2 & 0.0119 & 0.0059 & 2.86 & 0.098 \\
Depth of cut & 2 & 0.0596 & 0.0298 & 12 & 0.005 \\
Error & 2 & 0.0098 & 0.0049 & & \\
Total & 8 & 0.0904 & & & \\
\hline $\mathrm{S}=0.0452$ & \multicolumn{2}{l}{ R-sq=98.24\% } & \multicolumn{2}{c}{ R-sq $(\operatorname{adj})=90.21 \%$}
\end{tabular}

\subsection{Validation Test for Grey Relational Grade}

After an optimum combined process level for output responses has been reached, validation tests are required to verify the accuracy of analysis. Table 15 shows the comparison of the optimum process parameter experimental greyscale values with the predicted grayscale values of the optimum process parameters. However, the grey relation grade from the combined initial process parameter to the optimal process parameter combination has been increased by 0.10 .

Table 15 - Results for the confirmation tests

\begin{tabular}{lccc}
\hline \multirow{2}{*}{ Initial process parameter } & \multicolumn{2}{c}{ Optimal process Parameters } \\
\cline { 3 - 4 } & & Prediction & Experiment \\
\hline Level & $\mathrm{A} 1 \mathrm{~B} 1 \mathrm{C} 1$ & $\mathrm{~A} 3 \mathrm{~B} 2 \mathrm{C} 1$ & $\mathrm{~A} 3 \mathrm{~B} 2 \mathrm{C} 1$ \\
$\mathrm{Ra}$ & 1.41 & & 1.26 \\
$\mathrm{~F}_{\mathrm{D}}$ & 1.05 & & 1.01 \\
Grey relational grade & 0.505 & -1.58 & 0.627 \\
\hline
\end{tabular}

Improvement of Grey relational grade $=0.10$

\section{Machined Surface Topography Analysis}

Machined surface characteristics of CFRP composites were systematically analyzed by scanning electron microscopy. There is a need to examine the surface damages and surface excellence in milling of CFRP composites for thorough investigation.

\subsection{Influence of Process Parameters on Machined Surface by SEM Analysis}

Selection of machining process parameters is important to restrict the milled surface damages and improves the milling quality. There is a need to correlate the experimental results with surface topology of milling CFRP composites. SEM analysis is essential to know the damage mechanisms and fibre, matrix behavior in composite arrangement. Usually, thrust force is increases with increasing of feed rate, consequently, chip thickness is increases and higher values of SR and DLF was found [30]. In this study, beyond feed rate of $200 \mathrm{~mm} / \mathrm{min}$ surface integrity damage (failure initiation and flaw propagation) was observed from Figures 7a, b, and c. Depth of cut had considerable effect on performance characteristics (SR and DLF). In this context, depth of cut is increased from $0.5 \mathrm{~mm}$ to $2.5 \mathrm{~mm}$, obtained SR and DLF is increased from $1.26 \mu \mathrm{m}$ to $2.36 \mu \mathrm{m}$ and 1.01 to 1.12 , where more forces were profound may cause interplay separation and delamination can be seen in bottom ply. Which may further fibre breakage occur by inter-laminar separation even tool is completely engaged with workpiece at high depth of cuts. It is evident that deteriorates the surface quality attains at higher depths of cuts was seen in Fig.7. a. Crack initiation of fibre b. Fibre-Matrix separation. c. Smear off epoxy and plough up of fibres. Nevertheless, the material removal process become easy, the specific energy tends to decreases at the instance of spindle speed is increasing from 1000rpm to 4000rpm. At higher spindle speeds obtained lower SR and DLF are $1.26 \mu \mathrm{m}$ and 1.01, respectively. Figure 8 details acceptable topography, and better machining effects (smooth 
cutting of fibre) were found at a higher spindle speed is $4000 \mathrm{rpm}$, lower depth of cut is $0.5 \mathrm{~mm}$ and moderate feed rate is $200 \mathrm{~mm} / \mathrm{min}$.

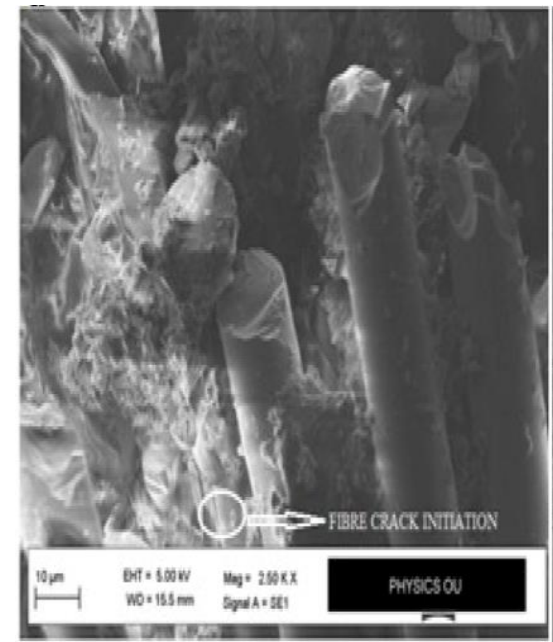

(a)

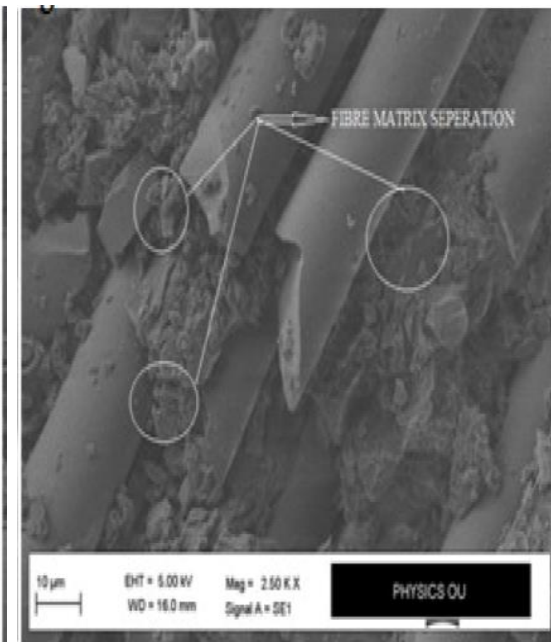

(b)

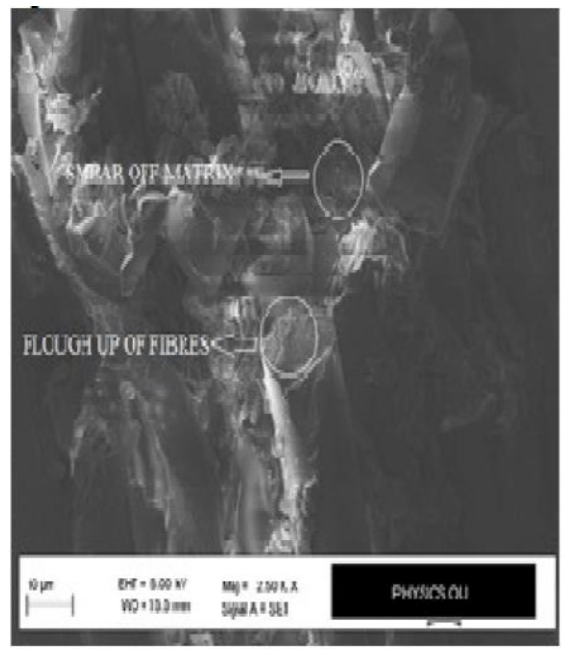

(c)

Fig. 7 - (a) SEM picture showing surface damage (Crack initiation of fibre) of CFRP composite, when spindle speed is $2500 \mathrm{rpm}$, feed rate is $200 \mathrm{~mm} / \mathrm{min}$, and depth of cut is $2.5 \mathrm{~mm}$; (b) SEM picture showing surface damage (Fibre-Matrix separation) of CFRP composite, when spindle speed is $1000 \mathrm{rpm}$, feed rate is $300 \mathrm{~mm} / \mathrm{min}$, and depth of cut is $2.5 \mathrm{~mm}$; (c) SEM picture showing surface damage (Smear off epoxy and plough up of fibres) of CFRP composite, when spindle speed is $1000 \mathrm{rpm}$, feed rate is $300 \mathrm{~mm} / \mathrm{min}$, and depth of cut is $2.5 \mathrm{~mm}$

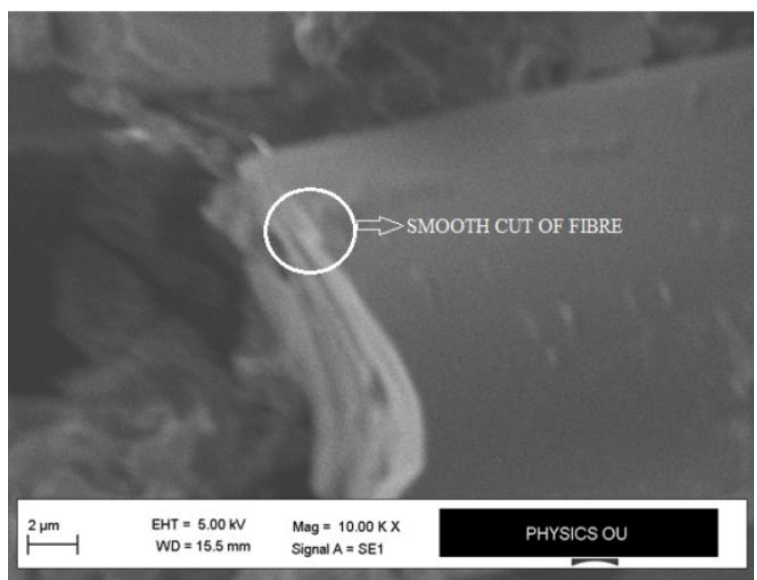

Fig. 8 - SEM micrograph showing better surface quality (Smooth cut of fibre) of CFRP composite, when spindle speed is $4000 \mathrm{rpm}$, feed rate is $200 \mathrm{~mm} / \mathrm{min}$, and depth of cut is $0.5 \mathrm{~mm}$

\section{Conclusions}

i. The spindle speed and the feed rate have no significant effect on the SR and DLF of CFRP composite laminates.

ii. For optimization of typical multiple performance characteristics could be simplified and improved by GreyTaguchi method. From the response table it is established that largest value for the GRG for the spindle speed is of $4000 \mathrm{rpm}$, feed rate of $200 \mathrm{~mm} / \mathrm{min}$, and depth of cut of $0.5 \mathrm{~mm}$ (A3B2C1).

iii. Depth of cut has the most significant role for influencing the SR and DLF. Cutting depth is an important parameter that has a heavy spindle speed interaction to influence the SR and DLF.

iv. As seen in this study, when SEM analysis is correlated with experimental results, it was found that better surface quality could be obtained at a lower depth of cut is $0.5 \mathrm{~mm}$, moderate feed rate is $200 \mathrm{~mm} / \mathrm{min}$ and at a higher spindle speed is 4000rpm.

v. From SEM illustration, more damage mechanism were found at higher a depth of cuts of $2.5 \mathrm{~mm}$, higher feed rates of $300 \mathrm{~mm} / \mathrm{min}$, and lower spindle speeds of 1000rpm. 


\section{References}

[1] Jahanmir, S., Ramulu, M., Koshy, P., (2000). Machining of Ceramics and Composites. Marcel Dekker, Inc., New York, 1-694

[2] Smith, W. F..,(1990). Principles of Materials Science and Engineering. McGraw-Hill, US, 743-768.

[3] M. Ramulu, C.W. Wern, J.L. Garbini., (1993). Effect of the direction on surface roughness measurements of machined graphite/epoxy composite. Compos. Manuf., 4 (1), 39-51

[4] Erisken, E.,(1999). Influence from production parameters on the surface roughness of a machine short fibre reinforced thermoplastic. Int. J. Machine Tools Manuf., 39(10), 1611-1618

[5] Sreejith,P.S., Krishnamurthy,R., Malhota,S.K., Narayanasamy, K., (2000). Evaluation of PCD tool performance during machining of carbon/ phenolic ablative composites. J. Mater. Process. Technol., 104(1-2), 53-58

[6] Everstine, G.C., Rogers, T.G., (1971). A theory of machining of reinforced materials. J. Compos. Mater., 5, 94-106

[7] Koplev, A., Lystrup,A., Vorm, T., (1983). The cutting process. Composites., 14 (4), 371-376

[8] Kaneeda, T., (1989). CFRP Cutting mechanism. Proceeding of the 16th North American Manufacturing Research Conference. 216-221

[9] Puw, H.Y., Hocheng, H., Kuo, H.C., (1995). Anisotropic chip formation models of cutting of FRP. Proceedings of ASME Symposium on Material Removal and Surface Modification Issues in Machining Processes, New York, 259282

[10] Santhanakrishman,G., Krishnamurthy, R., Malhota., S.K., (1988). Machinability characteristics of fibre reinforced plastics composites. J. Mech. Working Technol., 17, 195-204

[11] Ramulu, M., Arola, D., Colligan, K., (1994). Preliminary investigation of effects on the surface integrity of fibre reinforced plastics. Engineering Systems Design and Analysis, ASME, 64(2), 93-101

[12] Hocheng, H., Puw, H.Y., Huang, Y., (1993) Preliminary study on milling of unidirectional carbon fibre reinforced plastics. Compos. Manuf., 4 (2), 103-108

[13] Enemuoh, Ugo E., El-GizawySherif A., Okafor A., (2001). An aproach for development of damage-free drilling of carbon fibre reinforced thermosets. International Journal of Machine Tools and Manufacture., 41(12), 1795- 1814

[14] Paulo Davim, J., Pedro Reis, Conceicao Antonio, C., (2004). Experimental study of drilling glass fibre reinforced plastics (GFRP) manufactured by hand lay-up. Composites Science and Technology., 64, 289-297

[15] Prashanth, I.S.N.V.R., Ravishankar, D.V., Manzoor Hussain, M., Chandra Mouli, Badiganti. (2017). Critical Analysis in Milling of GFRP Composites by Various End Mill Tools. Materials Today: Proceedings., 5, 1460714617, Elsevier

[16] Sheikh-Ahmad, Twomey, J., Kalla, D., Lodhia, P., (2007). Multiple regression and committee neural network force prediction models in milling FRP. Machining Science and Technology., 11 (3), 391-412

[17] Kalla, Devi., Sheikh-Ahmad, Jamal., Janet M, Twomey., (2010). Prediction of cutting forces in helical end milling fibre reinforced polymers. International Journal of Machine Tools \& Manufacture., 50, 882-891

[18] Prashanth, I.S.N.V.R., Ravishankar, D.V., Manzoor Hussain, M., Chandra Mouli, Badiganti., Vinod Kumar, Sharma., Sunil, Pathak., (2018). Investigations on Performance characteristics of GFRP Composites in Milling. The International Journal of Advanced Manufacturing Technology., 99, 1351-1360

[19] Deng, J. L., (1989). Introduction to Grey system. The Journal of Grey System., 1, 1-24

[20] Palanikumar, K., (2006). Cutting parameters optimization for surface roughness in machining of GFRP composites using Taguchi's method. Journal of Reinforced Plastics and Composites., 25(16), 1739-1751

[21] Gupta, M., Kumar, S., (2013). Multi-objective optimization of cutting parameters in turning using grey relational analysis. International Journal of Industrial Engineering Computations., (4), 547-558

[22] Sadasiva, R., Rajesh, V., Venu Gopal, A., (2012). Taguchi based Grey Relational Analysis to optimize face milling process with multiple performance characteristics. International Conference on Trends in Industrial and Mechanical Engineering, Dubai, (ICTIME)

[23] Arun Kumar, Parida., Rajesh Kumar, Bhuyan., Bharat Chandra, Routara., (2014). Multiple characteristics optimization in machining of GFRP composites using Grey relational analysis. International Journal of Industrial Engineering Computations., 5(4), 511-520

[24] Jenarthanan, M.P., Venkata Sai Sunil, Gujjalapudi., Venkatraman, V., (2017). Multi-objective optimization in endmilling of glass fiber reinforced polymer composites using desirability functional analysis and grey relational analysis. Multidiscipline Modeling in Materials and Structures., 13(3), 391-408

[25] Naresh, N., Jenarthanan, M.P., Hari Prakash, R, (2014). Multi-objective optimization of CNC milling process using Grey-Taguchi method in machining of GFRP composites. Multidiscipline Modeling in Materials and Structures., 10(2), 265-275

[26] Panneerselvam, K., Pradeep, K., Asokan, P., (2012). Optimization of end milling parameters for Glass Fiber Reinforced Plastic (GFRP) Using Grey Relational Analysis. Procedia Engineering., 38, 3962-3968

[27] Rajguru, R.R., Hari, Vasudevan.,. Deshpande, N.C., (2013). Analysis of a Multi-criteria optimization problem using Taguchi and Grey relational analysis: A case study in the machining of composite materials. Proceedings of International Conference on Advances in Mechanical Engineering, ICAME, 1-6 
[28] Vinod Kumar Sharma, Sunil Pathak, I.S.N.V.R. Prasanth, D.V. Ravishankar, M. Manzoor Hussain, Chandra Mouli Badiganti, and Nagaraju Bejgam (2020). Influence of milling process parameters on the surface quality of GFRP composites. In Glass Fibre-Reinforced Polymer Composites. Walter DE GRUYTER, eISBN: 9783110610147. GmbH . Genthiner Str. 13. 10785 Berlin. Deutschland. Chapter 5, Pp:69-83

[29] Paulo, Davim., Pedro, Reis., (2005). Damage and dimensional precision on milling Carbon fiber-reinforced plastics using design of experiments. Journal of Materials Processing Technology, 100(2), 160-167

[30] Jamal Y. Sheikh-Ahmad., (2009). Machining of Polymer Composites. Abu Dhabi, UAE, 1-321 